\title{
RADIATION FROM DIFFERENT PARTS OF LAPTOPS
}

\author{
USIKALU M. R, SONEYE O \& AKINPELU A
}

Department of Physics, Covenant University Ota, Ogun State, Nigeria

\begin{abstract}
Radiation from laptop cannot be seen by the naked eyes, but it can pose real dangers to our health. If only we are a few feet away to our laptops, otherwise when laptops are placed and used directly on our laps, it exposes us to quite more intense radiation that are harmful. It has been said that the amount of radiation emitted by desktop computers is generally higher than that which is emitted from laptop or notebook computers. And the use of small-sized components, a Light Emitting Diode (LED) or Liquid Crystal Display (LCD) are some of the main reasons why that is so. Furthermore, these laptops are battery operated and this plays a major role in reducing the rate of radiation emitted from these portable devices. But internal parts of laptop heat up and radiate. There is a generation of Extremely Low Frequency (ELF) by laptop from storage and computing processing. Placing the laptop on the lap makes it to be very close to the genitals, skin and muscles. Prolonged exposure to this radiation may produce biological effects on human health. This work used Cell Sensor manufactured by Action Electronic, USA to detect ELF from fourteen (14) laptops and mini laptops. It was found that the keyboard of the laptop emitted highest value of ELF radiation while the back of the laptop had the lowest ELF radiation. The highest $E L F$ at $0 \mathrm{~cm}$ for different parts measured are $5 \mathrm{mG}, 5 \mathrm{mG}, 3.5 \mathrm{mG}$ and $0.7 \mathrm{mG}$ for laptop keyboard, mouse pad, fan and screen respectively. There is no ELF measured at the back of the laptops except in AMP with ELF of $0.1 \mathrm{mG}$ at $0 \mathrm{~cm}$. It was observed and discovered that mini laptops emitted low ELF radiation than laptops of size ranging from 14 inches - 17 inches. Therefore, this study suggested that less often the laptops are placed on the laps the more the health and safety of the users are guaranteed.
\end{abstract}

KEYWORDS: Extremely Low Frequency, Laptops, Radiation, Cell Sensor \& Health Effects

Received: Jul 04, 2018; Accepted: Jul 25, 2018; Published: Aug 29, 2018; Paper Id.: IJMPERDOCT201819

\section{INTRODUCTION}

Laptops contain fans embedded in them that exhaust hot air that is above 110 Fahrenheit most of the time. The operating temperature is kept stable in the computer by these fans thereby ensuring the best performance, but potential harmful effects in users is as a result of exposure to exhaust hot air. Electromagnetic Fields (EMFs) is released when converting energy to perform the range of functions of the laptop (Diffen, 2012). This EMFs is in the low frequency range and then give off from the external shell of the computer from sources like hard drive operations, processor activities, memory storage and some during other computing processes. Laptops are used to connect to the internet, tablets like iPads and other computer devices by means of technologies for instance Bluetooth, 4G and Wi-Fi. The receiver and transmitter of a laptop make these connections possible. When a laptop is placed on the lap, it radiates radio frequency produced by transmitter and this is absorbed directly by the body. Also, the various components that make a laptop function are positioned just under the keyboard and mouse pad of the laptop. Considering that users use both the keyboard and mouse pad of a laptop every time they make use of one, they are exposed to the ELF radiation generated by these components. The three types of radiation emitted from laptop computers are heat radiation, low frequency Electromagnetic Radiation (EMF) and Radio Frequency 
(RF) radiation (Lucas, 2015; Radha and Gurupranesh, 2014). These three radiations can pose danger to the health. Although there are other sources that these radiations can be gotten from like desktop computers, televisions, cell phones and microwave ovens. Laptop's radiation exposure is more intense because laptops are operated directly on laps. These radiations could actually be harmless if laptops are placed a few feet away. Notebook or laptop does have similar radiation and their radiation is generally lower than what desktop PC's dissipates since the components are smaller. The screen is customarily LCD or LED and the laptop is operated mainly with battery. Radiation from the laptop is 1 miligaus (mG) at $30 \mathrm{~cm}$ and as much as 20 milligaus $(\mathrm{mG})$ at $0 \mathrm{~cm}$ and this $20 \mathrm{mG}$ does have severe health effects, because all the three types of radiation mentioned above are close to the genitals, skin and muscle. This radiation could create bodily reactions such as skin rashes, muscle soreness and infertility. If electronic radiation exposure and heat from the laptop is in high levels it could cause fatigue, headache, dizziness, breathlessness and different types of cancer.

Perez-Vega et al (2000) performed measurement of radiation from screens at $2.5 \mathrm{~m}$ from the screen of several receivers using a simple Geiger-Muller counter. In all the observed cases, exposure rates produced by PC monitors and TV receivers were higher than that of background radiation. They reported values for various measurement conditions. The values were: background radiation - $0.0107 \mathrm{mR} / \mathrm{h}$; PC monitor off (background) $-0.011 \mathrm{mR} / \mathrm{h} ; \mathrm{PC}$ monitor at $5 \mathrm{~cm}$ in front of screen - $0.0132 \mathrm{mR} / \mathrm{h}$; PC monitor at $5 \mathrm{~cm}$, lateral $-0.0132 \mathrm{mR} / \mathrm{h}$; PC monitor at $5 \mathrm{~cm}$ in front of the screen, with filter $0.013 \mathrm{mR} / \mathrm{h}$; PC monitor at $50 \mathrm{~cm}$, front $-0.0136 \mathrm{mR} / \mathrm{h}$; TV receiver at $2.5 \mathrm{~m}-0.0154 \mathrm{mR} / \mathrm{h}$; Computer room (20PC's) $0.015 \mathrm{mR} / \mathrm{h}$. The presence of ELF radiation above the background level in mobile phone and monitors had been confirmed by (Usikalu and Akinyemi, 2007; Akinyemi and Usikalu, 2010). A biological effect occurs when a change can be measured in a biological system after the introduction of some type of stimuli. However, the observation of a biological effect does not conclusively suggest the existence of a biological hazard or health effect. However, a biological effect only becomes a safety hazard when it causes a detectable impairment of the health of the individual or of his or her offspring (ICRP, 1991). Biological effects could be physiological, biochemical or behavioural changes induced in an organism, tissue or cell. Radiation can affect the body in many ways, and the health effect may not become apparent for many years. These effects range from mild symptoms, such as skin reddening to serious effects such as cancer and death. These effects are dependent upon the amount of radiation absorbed by the body (the dose), the type of radiation, whether or not the exposure was internal or external, and the length of exposed time (Haddow et al., 2008). All populations are now being exposed to varying degrees of man-made sources of Electro Magnetic Fields (EMF's) and the exposure levels will likely continue to increase as technology inventions advance.

There is always an interaction between non ionizing radiations with tissue through heat generation. The absorption characteristics of different tissues and ability to penetrate human body determine the level of hazards. Following the initial epidemiological study on childhood, cancer is a great number of other diseases that have been studied in relation to ELF fields (Ank, 2013; Aweda et al., 2010). These diseases include cardiovascular disease, neurodegenerative disease and psychiatric disorders. The heart rate variability effect discovered in laboratory work was the foundation for the assumption that exposure to ELF might influence the risk of cardiovascular disease and a number of epidemiologic results supported by IARC (2002), Although, well controlled research performed later have dismissed this assumption. However, many neurodegenerative diseases are still believed worthy of studying, in particular about Amyotrophic Lacteral Sclerosis (ALS) and Alzheimer disease (Ahlbom, 2011). Nerves and muscle cells are known to be affected by ELF magnetic fields, although little evidence was reported for nervous system or behaviour at environmental exposure levels. The study on the effect of ELF magnetic fields on embryonic development of non-mammalian species like birds have been suggested by 
many independent researchers. The evidence in mammalian species is limited to inconsequential skeletal anomalies discovered in various studies with mice and rats. The general discoveries in teratological studies on rodents and minor skeletal variations are most of the time considered insignificant biologically (Bernhardt et al., 2003). Therefore, it is imperative to assess the ELF emanating from different parts of the laptop and make useful advice on best practices to adopt in using laptops.

\section{METHODOLOGY}

The device used in measuring the Extremely Low Frequency (ELF) radiation from various laptops was the Cell Sensor manufactured by Action Electronic, USA. The cell sensor is a radio frequency detection meter which is also capable of being used as an extremely low frequency detection meter. Cell sensor possesses a remote probe that when connected to the unit makes it an extremely low frequency detection meter. It is primarily for radio frequency detection. When the probe is connected to the main unit, it allows one to measure fields in all places, while making it easy to watch the readings on the display unit of the meter. The device measures ELF fields in milligauss (mG) and is shown on the bottom scale of the display marked 'Power (ELF)' in green print. The meter measures in two different ELF scales. The device has a switch on the side that makes it possible to switch between high sensitivity and normal sensitivity. The high sensitivity scale is about 1 to 5 milligauss (mG) while the normal sensitivity scale is from 1 to 50 milligauss (mG). The scale is however only marked with the high sensitivity scale so it is up to the user reading the scale as though it were marked 1 to 50 when in normal sensitivity mode (Usikalu and Akinyemi, 2012).

Taking the readings involved first isolating the source of ELF. The probe is then positioned next to the point at which reading is to be taken from. Once close to the source, the needle on the display deflects. To get accurate readings, the probe was rotated in different directions; horizontally, vertically and sideways and the display unit displayed the measured values. At this point, the interior coil of the meter was best aligned with the source of ELF and it will produce a more precise measurement of the field.

Fourteen (14) laptops were used for the experiment. The laptops were gathered from different staff and students of Covenant University. The laptops with codes used were: HP (HP1), ASUS (ASU), HP 250 (HP2), HP Pavilon dv6 (HPD), HP Pavilon g6 (HPG), HP Elitebook 6930P (HPE), Apple MacBook Pro 2015 (AMP), Apple MacBook Air (AMA), HP Pavilon (HPP), HP Chromebook (HPC), Dell Inspiron (DI), Compaq Presario CQ56 (CPC), HP Mini Notebook (HPM) and HP Notebook (HPN). The laptops used were placed on a table $50 \mathrm{~cm}$ on each side away from any other source of radiation to avoid external radiation adding up to the radiation from the laptops. The laptops were unplugged from external power supply to ensure the radiation reading obtained and displayed on the Cell Sensor was solely produced by the laptops. The ELF radiation was taken from different parts of the laptops which were mouse pad, keyboard, fan, screen and back of the laptop

The laptops were turned on and allowed to run for 5 minutes with no programs running. Data was acquired to observe the ELF radiation emitted during start-up. The probe of the Cell Sensor was positioned at the specific parts of the laptop from which ELF radiation was to be taken. A meter rule was used in measuring the distance from the parts. For the mouse pad, the meter rule was placed perpendicularly. The probe was first placed on the mouse pad to observe how much ELF radiation was being emitted at $0 \mathrm{~cm}$. The value was recorded. The probe was then moved to $5 \mathrm{~cm}$ away from the mouse pad and the reading was taken. The procedure was repeated up to $30 \mathrm{~cm}$ from the mouse pad at regular intervals of 
$5 \mathrm{~cm}$. The procedure was repeated different parts of the laptops.

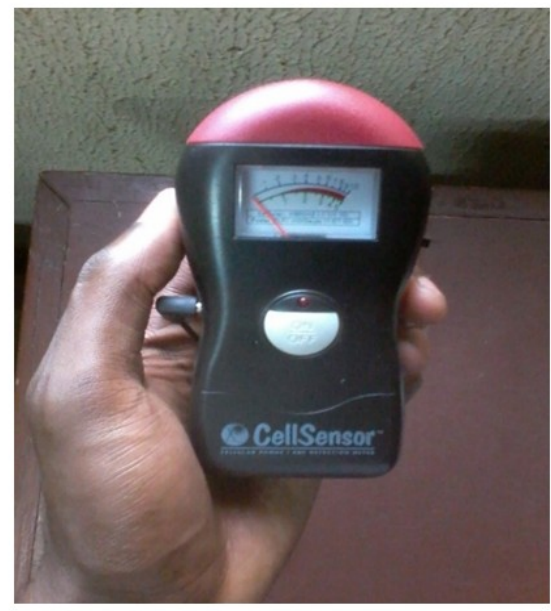

(a) Front View of Cell Sensor

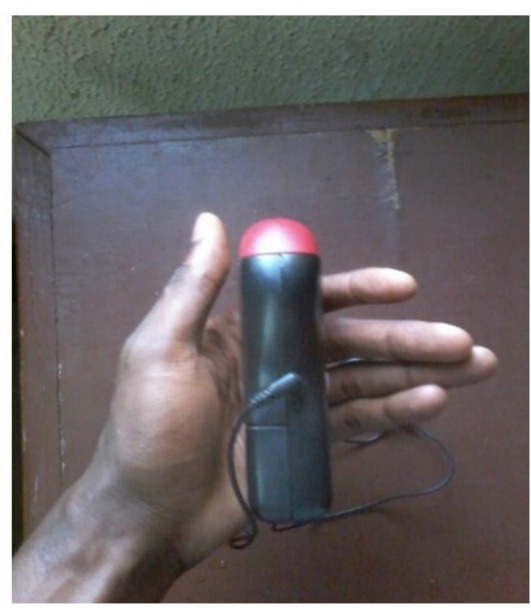

(b) Side View of Cell Sensor

Figure 1

\section{RESULTS AND DISCUSSIONS}

The ELF radiation obtained from the screen of the laptops ranged between $0.1-0.7 \mathrm{mG}$ for distances between $0-$ $30 \mathrm{~cm}$ as shown in Table 1. HPG had the highest ELF radiation level of $0.7 \mathrm{mG}$ at $0 \mathrm{~cm}$. Even at $40 \mathrm{~cm}, \mathrm{HPG}$ still had ELF radiation of $0.05 \mathrm{mG}$. HPE, HP2, HPC and HPM had the lowest ELF radiation level of $0.1 \mathrm{mG}$ at $0 \mathrm{~cm}$ and practically 0 $\mathrm{mG}$ at $30 \mathrm{~cm}$. The ELF radiation obtained from the screen after the laptop had been ON for 1 hour was the same value as the one obtained at start-up.

The ELF radiation obtained from the mouse pad of the laptops ranged from as $0-5 \mathrm{mG}$ for distances between $0-$ $30 \mathrm{~cm}$. Figure 2 is the pictorial presentation of the ELF value measured in the mouse pad of the fourteen laptops used in the study. It was discovered that HPE has the lowest ELF value of $0.5 \mathrm{mG}$ at $5 \mathrm{~cm}$ away from the mouse pad while AMP, HPG, HPD, AMA, HP1 and CPC have the highest ELF radiation value of $5 \mathrm{mG}$ each at $5 \mathrm{~cm}$ away from the mouse pads. Laptops such as ASU and HPE had the lowest ELF radiation of $2 \mathrm{mG}$ at $0 \mathrm{~cm}$. It is believed that this is due to the presence of the major electronics and electrical components directly under the mouse pad. These components make the laptop function and in the process they give off ELF radiation in the form of heat. However, there is a gradual reduction in the ELF measured as the Cell Sensor is moved away from the mouse pad. The ELF radiation measured after 1 hour is the same as $5 \mathrm{mG}$ at $0 \mathrm{~cm}$. 
Table 1: ELF Radiation (mG) from Laptop Screen

\begin{tabular}{|c|c|c|c|c|c|c|}
\hline LAPTOPS & $\mathbf{0} \mathbf{~ c m}$ & $\mathbf{5} \mathbf{~ c m}$ & $\mathbf{1 0} \mathbf{~ c m}$ & $\mathbf{1 5} \mathbf{~ c m}$ & $\mathbf{2 0} \mathbf{~ c m}$ & $\mathbf{3 0} \mathbf{~ c m}$ \\
\hline HP1 & 0.2 & 0.1 & 0 & 0 & 0 & 0 \\
\hline ASU & 0.4 & 0.4 & 0.2 & 0.1 & 0 & 0 \\
\hline HP2 & 0.1 & 0 & 0 & 0 & 0 & 0 \\
\hline HPG & 0.7 & 0.5 & 0.3 & 0.2 & 0.2 & 0.1 \\
\hline HPD & 0.4 & 0.4 & 0.4 & 0.3 & 0.1 & 0 \\
\hline HPE & 0.1 & 0 & 0 & 0 & 0 & 0 \\
\hline AMP & 0.2 & 0.2 & 0.2 & 0.1 & 0.1 & 0 \\
\hline APA & 0.2 & 0.2 & 0.1 & 0.1 & 0 & 0 \\
\hline HPP & 0.3 & 0.2 & 0.2 & 0.1 & 0 & 0 \\
\hline HPC & 0.1 & 0.1 & 0 & 0 & 0 & 0 \\
\hline DI & 0.4 & 0.3 & 0.2 & 0.1 & 0.1 & 0 \\
\hline CPC & 0.6 & 0.4 & 0.3 & 0.2 & 0.2 & 0.1 \\
\hline HPM & 0.1 & 0 & 0 & 0 & 0 & 0 \\
\hline HPN & 0.2 & 0.2 & 0.1 & 0.1 & 0 & 0 \\
\hline
\end{tabular}

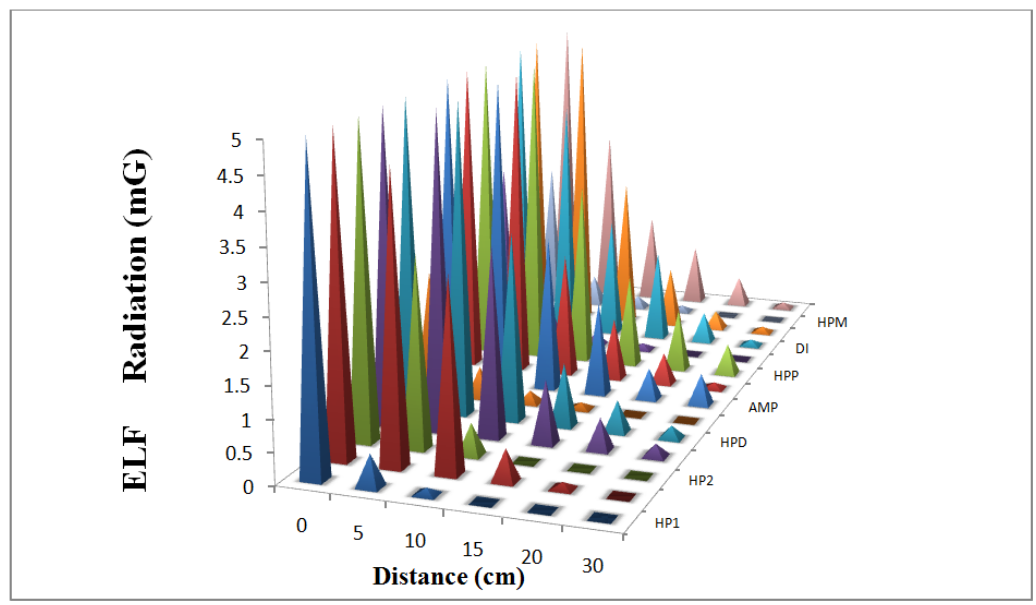

Figure 2: Variation of Mouse Pads ELFs of Different Laptop

The result obtained from the keyboard is more or less similar to that observed in the mouse pad. The ELF radiation is relatively high because it is located just above the electrical and electronics components of the laptop and it is not surprising to observe a similar pattern in the radiation. Figure 3 showed the measured ELF from the keyboard for different laptops. All the laptops under observation had ELF radiation of $5 \mathrm{mG}$ at $0 \mathrm{~cm}$. HPC and HMN had the lowest ELF radiation from the keyboard with a value of $0.4 \mathrm{mG}$ and $0.5 \mathrm{mG}$ at $5 \mathrm{~cm}$ respectively, while HP2 had a value of 1.0 $\mathrm{mG}$ at the same distance from the keyboard. The ELF radiation measured after 1 hour remained at $>5 \mathrm{mG}$ at $0 \mathrm{~cm}$. It was also noticed that HPC and HMN where the lowest ELF were recorded are both mini laptops (i.e. they are of smaller size than regular laptops), this may be attributed to the number of electronics components under the keyboard.

The ELF radiation obtained from the fan of the laptops ranged between $0.1-5 \mathrm{mG}$ at $0 \mathrm{~cm}$ as shown in Table 2 . HPE had the highest ELF radiation level of $5 \mathrm{mG}$ at $0 \mathrm{~cm}$. AMP and AMA had the lowest ELF radiation level of $0.1 \mathrm{mG}$ at $0 \mathrm{~cm}$ and practically $0 \mathrm{mG}$ at $5 \mathrm{~cm}$. The ELF radiation obtained from the fan after the laptop had been ON for 1 hour was the same value as the one obtained at start-up. There is no ELF radiation from the back of the laptops, except for the AMP which gave an ELF radiation value of $0.1 \mathrm{mG}$ at $0 \mathrm{~cm}$. All the laptops under observation had no detectable ELF radiation from the back of the laptop and the ELF radiation measured at back of the laptops after 1 hour remained $0 \mathrm{mG}$ even for the AMP. The mean ELF radiation from the different parts of all the laptops under observation at various distances is 
displayed in Figure 4. Generally from from the measurement of different parts of a computer, it was observed that ELF decreased with distance which in consonance with the reports of (Akinyemi et al., 2011 and Usikalu et al., 2018). This revealed that the ELF radiation measured can be summarized as: back $<$ screen $<$ fan $<$ keyboard $<$ mouse pad.

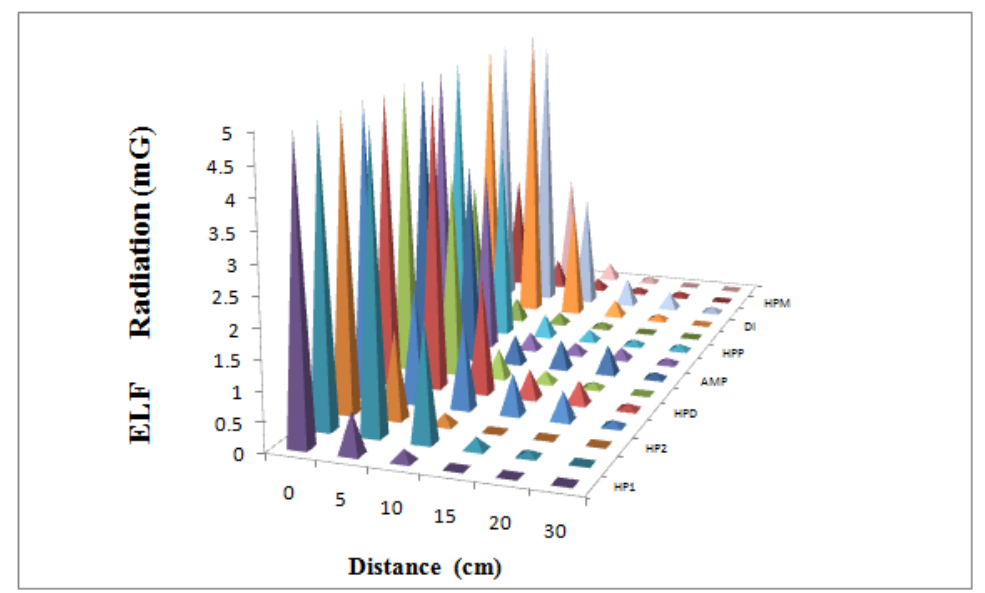

Figure 3: ELFs of Keyboards with Respect to Distance

Table 2: ELF Radiation (mG) from Laptop Fan

\begin{tabular}{|c|c|c|c|c|c|c|}
\hline LAPTOPS & $\mathbf{0 ~} \mathbf{~ c m}$ & $\mathbf{5} \mathbf{~ c m}$ & $\mathbf{1 0} \mathbf{~ c m}$ & $\mathbf{1 5} \mathbf{~ c m}$ & $\mathbf{2 0} \mathbf{~ c m}$ & $\mathbf{3 0} \mathbf{~ c m}$ \\
\hline HP1 & 2.5 & 0.5 & 0.3 & 0.1 & 0 & 0 \\
\hline ASU & 3 & 0.2 & 0.1 & 0 & 0 & 0 \\
\hline HP2 & 1.5 & 1 & 0.2 & 0 & 0 & 0 \\
\hline HPG & 3.5 & 2 & 0.5 & 0.2 & 0 & 0 \\
\hline HPD & 3 & 1.2 & 0.7 & 0.1 & 0 & 0 \\
\hline HPE & 5 & 4 & 0.5 & 0.2 & 0 & 0 \\
\hline AMP & 0.1 & 0 & 0 & 0 & 0 & 0 \\
\hline APA & 0.1 & 0 & 0 & 0 & 0 & 0 \\
\hline HPP & 3 & 1.5 & 1.0 & 0.2 & 0 & 0 \\
\hline HPC & 1.2 & 0.2 & 0.1 & 0 & 0 & 0 \\
\hline DI & 2.5 & 0.8 & 0.5 & 0.2 & 0 & 0 \\
\hline CPC & 3.4 & 2.1 & 0.7 & 0.2 & 0 & 0 \\
\hline HPM & 1.0 & 0.2 & 0.1 & 0 & 0 & 0 \\
\hline HPN & 1.5 & 1 & 0.3 & 0.1 & 0 & 0 \\
\hline
\end{tabular}

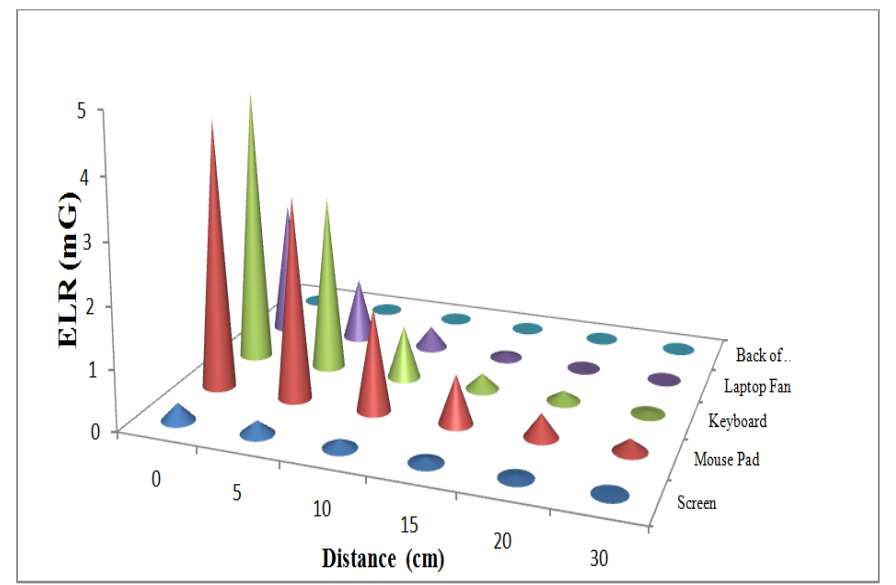

Figure 4: Comparison of the ELF Radiation (mG) from Various Parts of Laptops at Various Distances for all the Laptops 


\section{CONCLUSION}

In this work, we have confirmed the presence of ELF radiation above the background level to a minimum distance of $50 \mathrm{~cm}$ from the laptops, monitors, interactive monitor and CST Computer laboratory and ELF radiation decreases with distance. The part of a laptop that emitted highest value of ELF radiation was the keyboard while the back of the laptop had the lowest ELF radiation. It was revealed from the study that the ELF radiation does not increase within 1 hour of operation of the laptops. Comparing the obtained ELF values from radiations from a laptop keyboard suggests that mini laptops emit less ELF radiation than laptops of size ranging from 14 inches -17 inches. The research hereby recommended the use of the mini laptops among students and everyone in the society. It further suggested the use of external peripherals or wireless keyboard and mouse instead of direct use of the laptop's keyboard and mouse pad. Also, government should scrutinise the importation of laptops into the country as laptops with low ELF only should be imported.

\section{REFERENCES}

1. Ahlbom A (2001). Neurodegenerative diseases, suicide and depressive symptoms in relation to EMF. Bioelectromagnetics, Suppl 5(16): S 132-43

2. Akinyemi M. L, Kayode J. S and Usikalu M. R (2011). Investigation of Extremely Low Frequency (ELF) Hot Spots in the College of Science and Technology, Covenant University, Ota, Turkish Journal of Physics 35(3): 359-361.

3. Akinyemi, M. L and Usikalu, M. R. (2010). Prudent avoidance in exposure to extremely low frequency (ELF) fields. Scientific Research and Essays. 5, 2295-2298

4. Ank, A. (2013). Computer Radiation: the risks, effects and protection from Electromagnetic radiation. Retrieved from Topics:Whatsoever:http://topicswhatsoever.blogspot.com.ng/2013/03/computer-radiation-the-risks-effects-and-protectionfrom-electromagnetic-radiation.html

5. Aweda M. A, Usikalu M. R.,Ding N, Wan J. H, Zhu J (2010). Genetoxic effects of 2.45 GHz microwave exposure on different cells of Sprague Dawley rats, International Journal Genetics and Molecular Biology, 2(9): 189-197.

6. Rajasekhar, E., \& Kumar, R. J. (2014). Experimental investigation of gamma radiation shielding characteristics of wood. International Journal of Humanities, 2, 21-26.

7. Bernhardt JH, Matthes R, McKinlay A, Vecchia P, Veyret B (2003). Exposure to Static and Low Frequency Electromagnetic Fields, Biological Effects and Health Consequences (0-100kHz) - Review of the Scientific Evidence and Health Consequences. Munich: International Commission on Non-Ionizing Radiation Protection

8. Diffen (2012). Difference: Electric and Magnetic Field. Retrieved from Diffen.com: http://www.diffen.com/difference/Electric_Field_vs_Magnetic_Field

9. Haddow, G., Bullock, J., \& Coppola, D. (2008). Introduction to emergency management. 3rd Edition. Oxford. Elvesier.

10. ICRP 1991 Recommendations of the International Commission on Radiological Protection Publication 60: 21 (1-3).

11. International Agency for Research on Cancer (IARC, 2002). Non- Ionizing Radiation, Part 1:Static and extremely lowfrequency (ELF) electric and magnetic fields. IARC Monographs on the Evaluation of carcinogenic Risks to Humans: Volume 80. Lyon: IARC Press

12. Lucas, J. (2015). Electromagnetism. Retrieved from Livescience.com: http://www.livescience.com/38169-electromagnetism.html 
13. Perez-Vega, C., Zamanillo, J. M., and Ipina, J. S. (2000). Assessment of Ionization Radiation from PC Monitors and TV Receivers. IEEE, 1048-1051.

14. Radha, R., and Gurupranesh, P. (2014). Electromagnetic Radiation from Electronic Appliances. Journal of Mechanical and Civil Engineering, 41-46.

15. Usikalu M. R and Akinyemi M. L (2012). Analysis of Radiation Dose around some Base Stations in Ota and Lagos Environ, International Journal of Basic and Applied Sciences, IJENS 12(5): 7-12.

16. Usikalu M. R, Babarimisa I. O, Akinwumi S. A, Akinyemi M. L, Adagunodo T. A and Ayara W. A (2018) Radiation from Visual Display Unit, IOP Conference Series: Earth and Environmental Science, Volume 173 (1): 012- 039.

17. Usikalu M. R. and Akinyemi M. L. (2007) Monitoring of radiofrequency radiation from selected mobile phones, Journal of Applied Sciences Research, 3(12): 1701-1704. 